\title{
Efficacy of CPET Combined with Systematic Education of Cardiac Rehabilitation After PCI: A Real-World Evaluation in ACS Patients
}

\author{
Quan-Yu Zhang · Qiang Hu • Yi Li · Yi Sun · Jing-Fei He · \\ Miao-Han Qiu · Jian Zhang · Yan-Chun Liang • Ya-Ling Han
}

Received: June 9, 2021 / Accepted: July 20, 2021 / Published online: August 5, 2021

(C) The Author(s) 2021

\section{ABSTRACT}

Introduction: There are scarce real-world data on the long-term efficacy and safety of cardiopulmonary exercise testing (CPET) combined with the systematic education of cardiac rehabilitation (CR) approach for patients postcoronary stenting, which is, therefore, the subject of this study.

Methods: Data collected between 1 April 2015 and 20 May 2017 from 11,345 patients in the rehabilitation center database at our hospital were retrospectively analyzed. Five hundred thirty-six patients with incomplete information, or unable to cooperate with telephone follow-up, were excluded; 4001 patients

Quan-Yu Zhang and Qiang Hu contributed equally to this work and should be considered co-first authors.

Supplementary Information The online version contains supplementary material available at https:// doi.org/10.1007/s12325-021-01871-y.

Q.-Y. Zhang · Q. Hu · Y. Li · Y. Sun · J.-F. He .

M.-H. Qiu ·J. Zhang · Y.-C. Liang Y.-L. Han ( $ه)$

Department of Cardiology, General Hospital of

Northern Theater Command, Shenyang 110016,

China

e-mail: hanyaling@263.net

Q. $\mathrm{Hu}$

Department of Cardiology, Xijing Hospital, Air Force Medical University, Xi'an 710032, Shanxi Province, China received the combined CR approach; and 6808 patients received only routine post-procedure education (controls). Of these, 2805 CR participants (CR group) were matched 1:1 to controls (control group) using propensity scores. The main outcome was quality of life in Seattle Angina Questionnaire (SAQ) scores. SAQ was measured in hospital and at follow-up; meanwhile, volume/type of habitual exercise, major adverse cardiovascular event (MACE), and its components of target vessel revascularization, myocardial infarction, and cardiac death were recorded and analyzed.

Results: At median 583 (range 184-963) day follow-up, compared with controls, the CR group showed fewer patients not engaging in physical exercise ( 22 vs. 956, $p<0.05$ ); more cumulative exercise time (h/week) $(8.22 \pm 6.17 \mathrm{~h} \quad$ vs. $3.00 \pm 1.65 \mathrm{~h}, \quad p<0.05)$; higher SAQ scores (physical limitation, $69.59 \pm 10.96$ vs. $57.49 \pm 7.19$; anginal stability, $80.50 \pm 18.21$ vs. $58.82 \pm 11.95$; anginal frequency, $78.58 \pm 11.07$ vs. $67.14 \pm 22.41$; treatment satisfaction, $82.33 \pm 13.21$ vs. $56.84 \pm 21.61$; quality of life, $68.69 \pm 18.33$ vs. $60.26 \pm 17.13$, all $p<0.01)$, but a similar MACE rate $(\log$-rank $p=0.621)$.

Conclusion: Compared with only routine postprocedure education, CR combining at least one-time CPET with a systematic cardiac education program before discharge improved engagement in physical activity and quality of life for patients after percutaneous coronary 
intervention (PCI) without increasing clinical adverse events.

Keywords: Cardiac rehabilitation; Quality of life; Percutaneous coronary intervention; Cardiopulmonary function exercise test; Coronary artery disease

\section{Key Summary Points}

Cardiac rehabilitation, especially exercise, may benefit post-percutaneous coronary intervention (PCI) patients with coronary heart disease; however, the average rate of cardiac rehabilitation is low, and there is no patient management scheme with strong operability yet.

Compared with only routine postprocedure education, cardiac rehabilitation combining cardiopulmonary exercise testing (CPET) with cardiac education could improve physical activity and quality of life for patients after PCI $(p<0.05)$.

Cardiac rehabilitation combining at least one-time CPET with a systematic cardiac education program before discharge improved engagement in physical activity and quality of life without increasing adverse events.

The conclusion of this article is helpful to promote our experience in China, which may benefit more patients and offer a good role in the Chinese cardiac rehabilitation field, and it may also provide a patient management scheme for post-PCI patients in other areas outside China.

\section{INTRODUCTION}

Despite significant improvement in prognosis and quality of life, patients with coronary heart disease who had undergone coronary stent implantation during the percutaneous coronary intervention (PCI) are not exempt from cardiac death, recurrent angina, decreased exercise tolerance, in-stent restenosis, anxiety, and depression [1-4]. However, it was reported that exercise training (i.e., cardiac rehabilitation, CR) after PCI improves coronary lumen loss, recurrent angina, and exercise tolerance [5-7], with the American Heart Association PCI guideline granting a class IA recommendation for medically supervised exercise programs [8]. However, in some areas such as China, the number of cardiovascular centers available for CR is $24 \%$. The average CR rate is $<10 \%$ in these centers [9], so efforts to raise awareness of the benefits of CR are warranted.

For years, we have continually and carefully carried out approaches to medically supervised exercise programs which might be the most suitable for post-PCI patients considering their particular socioeconomic, life/cultural, and physiological characteristics. We combined a one time cardiopulmonary function exercise test (CPET) and CR practice/education in the hospital and telephone health guidance/followup after discharge, and here we retrospectively analyzed the long-term efficacy and safety of the approach.

\section{METHODS}

\section{Data Collection}

The present single-center retrospective analysis was conducted to determine the effectiveness of one-time CPET in hospitals combined with systematic education of CR after stent implantation. From 1 April 2015 to 20 May 2017, 11,345 acute coronary syndrome (ACS) patients hospitalized for PCI were retrospectively screened; 536 patients were excluded because of incomplete information or inability/unwillingness to cooperate with telephone follow-up; 4001 patients received CR; and 6808 patients received routine postoperative education without CR (controls), as shown in Fig. 1. All data on baseline characteristics, medication, and clinical follow-up including Seattle Angina Questionnaire (SAQ) score were routinely collected 


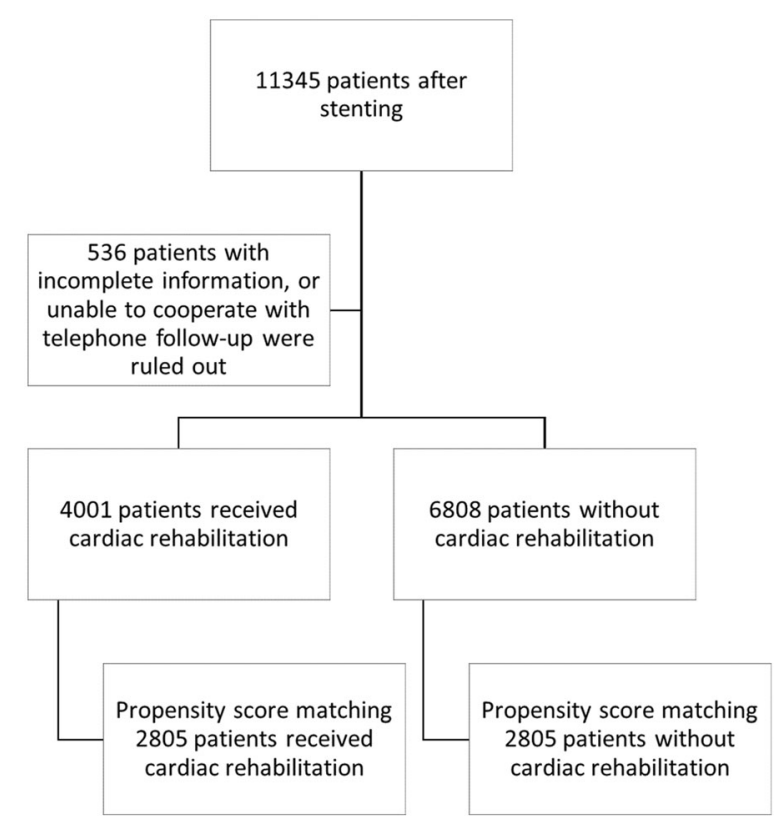

Fig. 1 Enrollment protocol

using the cv-net clinical data collection system (Beijing Crealife Technology Co., Ltd.) by a specialized clinical research team. CR was performed at the doctor's discretion after evaluation of the patient's overall health and socioeconomic status, disease severity, and willingness to undergo CR. Before CR, patients signed an informed consent form expressing understanding of the risks of CPET. All patients' clinical treatment and medications were optimized according to current PCI guidelines [10]. The Medical Ethics Committee of General Hospital of Northern Theater Command has approved our study and waived the need for patient consent. The data of patients in our study were not identifiable.

\section{Cardiopulmonary Function Exercise Test (CPET)}

CPET was performed by CARDIOVIT AT-104 PC Ergo-Spiro (SCHILLER) in the Heart Rehabilitation Center at our department. CPET is a diagnostic method that reflects the indexes of human cardiopulmonary function during exercise with increasing load. During CPET, the subjects' static electrocardiogram and static lung function (vital capacity/maximum ventilation) were individually collected. The patients were asked to breathe calmly, exhale forcefully to the limit after three or four times, then inhale forcefully to the limit, and then exhale forcefully. Cardiopulmonary function at different power levels and test results of exercise electrocardiography/exercise pulmonary function and cardiopulmonary function were also collected. The cardiopulmonary test entails four phases: resting phase (patient sitting on a vehicle, stationary for 1-2 min); warm-up phase (patient begins to pedal, no power load, pedal's speed at 40 times per minute, until the respiratory quotient steadily returns to about 0.85 ; lasts $2-3 \mathrm{~min}$ ); exercise phase (patient begins to pedal according to the previously configured power scheme and decides whether to terminate the power load according to the termination indication); and the recovery phase (patient keeps bicycling, no power load, depending on the recovery of heart rate to determine the end of the experiment; lasts 2-3 min). The test results of CPET including maximal oxygen uptake, metabolic equivalent (MET), and anaerobic threshold will be assessed for patients in the CR group. The rating of perceived exertion (RPE) will also be assessed using the Borg scale after CPET, which will be combined with other signs or symptoms to evaluate the cardiopulmonary function and exercise capacity. The indications for termination of CPET in our study were in accordance with the scientific statement from the American Heart Association [11].

\section{Systematic Education of CR After CPET}

After CPET, systematic prescription and education of CR for post-discharge were performed, which comprise rehabilitation exercises, nutrition, psychological intervention, smoking cessation, and medications according to the guidelines for coronary heart disease rehabilitation/secondary prevention [12]. Rehabilitation exercise prescription was individualized according to the maximum MET value suggested by CPET. Detailed exercise types and MET values are listed (see Table S1 in the 
electronic Supplementary Material for details). Exercise intensity and duration were adjusted every 3-6 months. The exercise was advised to be halted if any of the following occurred: (1) chest pain, dyspnea, or dizziness during or after exercise; (2) heart rate fluctuation $>30$ beats/ min; (3) blood pressure $>200 / 100 \mathrm{mmHg}$ or systolic blood pressure increase $>30 \mathrm{mmHg}$ or decrease > $10 \mathrm{mmHg}$; (4) electrocardiogram monitoring during exercise showed ST segment depression $\geq 0.1 \mathrm{mV}$ or elevation $\geq 0.2 \mathrm{mV}$; (5) severe arrhythmia occurred during or after exercise. Nutritional recommendations were individualized based on the principles of lower caloric intake, lower cholesterol intake, and balanced intake of fruits and vegetables. The psychological intervention was prescribed by a psychologist, while smoking cessation and medications were prescribed by clinical doctors. Finally, exercise type and volume of habitual exercise were routinely recorded by telephone follow-up after discharge.

\section{Outcomes Process}

The main outcome was quality of life as determined by SAQ scoring. The SAQ quantifies five domains, namely physical limitation (9 items), angina stability (1 item), angina frequency (2 items), treatment satisfaction (4 items), and quality of life (3 items), to assess angina and its impact on health and psychological status of the patients [13]. Degrees of physical limitation, angina stability, angina frequency, and treatment satisfaction from worst to best status ranged from 1 to 6 and quality of life from 1 to 5. SAQ scores overall and their components ranged from 0 denoting the worst to 100 denoting the best. Major adverse cardiovascular event (MACE) and its components of target vessel revascularization (TVR), myocardial infarction (MI), and cardiac death were recorded and analyzed [14]. MI [15] was defined as the presence of abnormal imaging findings of MI, clinical symptoms, or electrocardiographic changes combined with an increase in the creatine kinase myocardial band fraction above the upper normal limits or an increase in troponinT/troponin-I to $>$ 99th percentile of the upper normal limit. TVR was defined as subsequent revascularization of the target vessel by either PCI (additional stent or angioplasty) or coronary artery bypass grafting (CABG).

\section{Follow-up}

Via telephone interview, each patient completed the SAQ questionnaire and a detailed volume/type of habitual exercise questionnaire 1-3 months after discharge. Follow-up for clinical events was performed in 1, 3, 6, 12, 24, 36, 48 , and 60 months. Questions related to physical activity we prescribed were completed by all patients enrolled for analysis. The intensity of physical activity was categorized as mild $(<3$ METs), moderate (3-6 METs), and high intensity (> 6 METs) [16], as detailed in Table S1 in Supplementary Material. Cumulative exercise time was defined as the cumulative time of walking, light household activities, and exercise according to rehabilitation prescription.

\section{Statistical analyses}

Categorical variables are expressed by numbers (percentages) and were compared using the chisquare test or Fisher's exact test. Continuous variables are expressed as mean \pm SD or median and were compared using the independent $t$ test; 2805 CR participants were matched 1:1 to controls using propensity scores for a total of 5610 patients analyzed. A non-parsimonious model was used containing all variables in Tables 1 and 2. Pairs were matched by the nearest neighbor matching model. The covariate balance achieved was assessed by calculating the standardized differences in covariates between the two groups. A difference $<10 \%$ suggested the appropriate balance between groups. All tests were two-tailed. A $p$ value $<0.05$ was considered significant. $\mathrm{R}$ software was used for propensity score matching and SPSS 24.0 for statistical analyses. 
Table 1 Baseline characteristics of patients by study group before and after propensity score matching

\begin{tabular}{|c|c|c|c|c|c|c|c|}
\hline \multirow[t]{2}{*}{ Variable } & \multicolumn{3}{|c|}{ Before propensity score matching } & \multicolumn{4}{|c|}{ After propensity score matching } \\
\hline & $\begin{array}{l}\text { Control } \\
(N=6808)\end{array}$ & $\begin{array}{l}\text { CR } \\
(N=4001)\end{array}$ & $p$ value & $\begin{array}{l}\text { Control } \\
(N=2805)\end{array}$ & $\begin{array}{l}\text { CR } \\
(N=2805)\end{array}$ & $\begin{array}{l}\text { Standardized } \\
\text { difference }\end{array}$ & $p$ value \\
\hline Age (years) & $61.34 \pm 10.67$ & $57.42 \pm 9.46$ & $<0.01$ & $59.14 \pm 10.11$ & $58.89 \pm 8.96$ & 0.026 & 0.329 \\
\hline Men & $5040(74 \%)$ & $3108(77.7 \%)$ & $<0.01$ & $2114(75.4 \%)$ & $2095(74.7 \%)$ & 0.016 & 0.558 \\
\hline \multicolumn{8}{|c|}{ Type of acute coronary syndrome } \\
\hline Unstable angina & $4288(63 \%)$ & $3227(80.7 \%)$ & $<0.01$ & $2172(77.4 \%)$ & $2165(77.2 \%)$ & 0.006 & 0.823 \\
\hline STEMI & $1495(22 \%)$ & $415(10.4 \%)$ & $<0.01$ & $351(12.5 \%)$ & $353(12.6 \%)$ & 0.002 & 0.936 \\
\hline NSTE-ACS & $1021(15 \%)$ & $359(9 \%)$ & $<0.01$ & $282(10.1 \%)$ & $287(10.2 \%)$ & 0.006 & 0.825 \\
\hline Hypertension & $3992(58.6 \%)$ & $2213(55.3 \%)$ & $<0.01$ & $1571(56 \%)$ & $1519(54.2 \%)$ & 0.037 & 0.163 \\
\hline Diabetes & $1961(28.8 \%)$ & $893(22.3 \%)$ & $<0.01$ & $644(23 \%)$ & $674(24 \%)$ & 0.025 & 0.345 \\
\hline Smoking & $3254(47.8 \%)$ & $2307(57.7 \%)$ & $<0.01$ & $1552(55.3 \%)$ & 1567 (55.9\%) & 0.011 & 0.687 \\
\hline Previous PCI & $1406(20.7 \%)$ & $623(15.6 \%)$ & $<0.01$ & $446(15.9 \%)$ & $501(17.9 \%)$ & 0.052 & 0.054 \\
\hline Prior stroke & $387(5.7 \%)$ & $110(2.7 \%)$ & $<0.01$ & $93(3.3 \%)$ & $93(3.3 \%)$ & 0.000 & 1 \\
\hline Ejection fraction, \% & $57.76 \pm 8.67$ & $61.83 \pm 7.48$ & $<0.01$ & $60.53 \pm 7.03$ & $60.66 \pm 7.49$ & 0.018 & 0.491 \\
\hline
\end{tabular}

Data are presented as mean \pm SD or $n(\%)$. STEMI, ST segment elevation myocardial infarction; NSTE-ACS, non-ST segment elevation acute coronary syndrome

Table 2 Medication use by study group before and after propensity score matching

\begin{tabular}{|c|c|c|c|c|c|c|c|}
\hline \multirow[t]{2}{*}{ Medication } & \multicolumn{3}{|c|}{ Before propensity score matching } & \multicolumn{4}{|c|}{ After propensity score matching } \\
\hline & $\begin{array}{l}\text { Control } \\
(N=6808)\end{array}$ & $\begin{array}{l}\text { CR } \\
(N=4001)\end{array}$ & $\overline{p \text { value }}$ & $\begin{array}{l}\text { Control } \\
(N=2805)\end{array}$ & $\begin{array}{l}\text { CR } \\
(N=2805)\end{array}$ & $\begin{array}{l}\text { Standardized } \\
\text { difference }\end{array}$ & $p$ value \\
\hline Aspirin & $6803(99.9 \%)$ & 3997 (99.9\%) & 0.644 & $2805(100 \%)$ & $2805(100 \%)$ & 0.000 & 1 \\
\hline P2Y12 inhibitor & $6808(100 \%)$ & $4001(100 \%)$ & 1 & $2805(100 \%)$ & $2805(100 \%)$ & 0.000 & 1 \\
\hline ACEI/ARB & $5190(76.2 \%)$ & $3068(76.7 \%)$ & 0.597 & $2147(76.5 \%)$ & $2123(75.7 \%)$ & 0.020 & 0.452 \\
\hline$\beta$ blocker & $5153(75.7 \%)$ & $3252(81.3 \%)$ & $<0.01$ & $2244(80 \%)$ & $2228(79.4 \%)$ & 0.014 & 0.595 \\
\hline Nitrate & $4444(65.3 \%)$ & $2687(67.2 \%)$ & 0.046 & $1892(67.5 \%)$ & $1873(66.8 \%)$ & 0.014 & 0.589 \\
\hline Statin & $6719(98.7 \%)$ & $3995(99.9 \%)$ & $<0.01$ & $2802(99.9 \%)$ & $2799(99.8 \%)$ & 0.027 & 0.317 \\
\hline
\end{tabular}

\section{RESULTS}

\section{Long-term Results}

After exclusion of patients with incomplete information or unwilling/unable to participate in follow-up interviews, the total CR rate at our center was $37 \%$, and the longest follow-up period was 963 days, while the shortest followup period was 184 days, with a median followup of 583 days (Fig. 2); 2805 patients of the 4001 patients who received CR were 


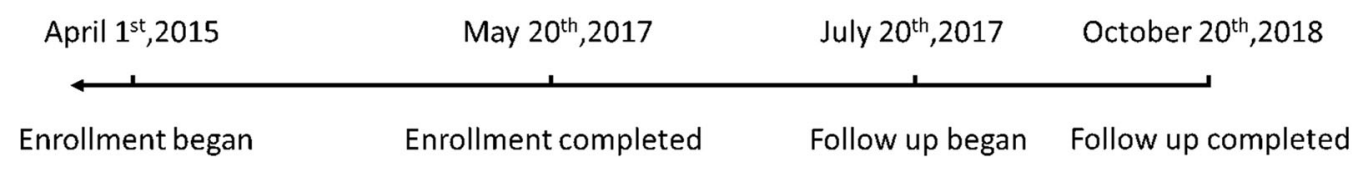

Fig. 2 Data collection and follow-up

Table 3 Physical activity categories and cumulative exercise time by study group

\begin{tabular}{llll}
\hline Physical activity & $\begin{array}{l}\text { CR } \\
(\boldsymbol{n}=\mathbf{2 8 0 5})\end{array}$ & $\begin{array}{l}\text { Control } \\
(\boldsymbol{n}=\mathbf{2 8 0 5})\end{array}$ & $\boldsymbol{p}$ value \\
\hline Mild & 22 & 956 & $<0.05$ \\
Moderate & 2736 & 1849 & \\
$\begin{array}{l}\text { High intensity } \\
\begin{array}{l}\text { Cumulative } \\
\text { exercise time }(\mathrm{h} /\end{array}\end{array}$ & 47 & 0 & \\
$\quad$ week $)$ & & $3.22 \pm 6.17 \pm 1.65$ & $<0.05$ \\
\hline
\end{tabular}

Physical activity was categorized into mild ( $<3$ METs), moderate (3 to $6 \mathrm{METs}$ ) and high intensity ( $>6 \mathrm{METs}$ ). Cumulative exercise time was defined as cumulative time of walking, light household activities, and exercise according to rehabilitation prescribed successfully matched to 2805 non-CR controls out of the 6808 controls eligible for matching (Fig. 1).

\section{Baseline Characteristics}

Baseline characteristics of patients before and after propensity score matching (PSM) are presented in Table 1. Before PSM, compared with controls, patients in the CR group had less severe conditions indicating that physicians were more likely to recommend CR for patients with less severe disease status. The patients in CR group were younger (61.34 \pm 10.67 vs. $57.42 \pm 9.46$ years, $p<0.01)$; more often men (74\% vs. $77.7 \%, p<0.01$ ); and presented less often with ST segment elevation acute myocardial infarction (STEM) (22\% vs. 10.4\%, $p<0.01$ ) and non-ST segment elevation elevation ACS (NSTE-ACS) $(15 \%$ vs. $9 \%, p<0.01)$ but more

Table 4 Seattle Angina Questionnaire score by domains and study group before and after propensity score matching

\begin{tabular}{|c|c|c|c|c|c|c|}
\hline \multirow[t]{2}{*}{ Seattle Angina Questionnaire } & \multicolumn{3}{|c|}{ Before propensity score matching } & \multicolumn{3}{|c|}{ After propensity score matching } \\
\hline & $\begin{array}{l}\text { Control } \\
(N=6808)\end{array}$ & $\begin{array}{l}\text { CR } \\
(N=4001)\end{array}$ & $p$ value & $\begin{array}{l}\text { Control } \\
(N=2805)\end{array}$ & $\begin{array}{l}\mathrm{CR} \\
(N=2805)\end{array}$ & $p$ value \\
\hline Physical limitation & $57.68 \pm 7.32$ & $69.82 \pm 11.26$ & $<0.01$ & $57.49 \pm 7.19$ & $69.59 \pm 10.96$ & $<0.01$ \\
\hline Anginal stability & $58.50 \pm 11.84$ & $80.52 \pm 18.29$ & $<0.01$ & $58.82 \pm 11.95$ & $80.50 \pm 18.21$ & $<0.01$ \\
\hline Anginal frequency & $65.07 \pm 23.67$ & $78.71 \pm 11.04$ & $<0.01$ & $67.14 \pm 22.41$ & $78.58 \pm 11.07$ & $<0.01$ \\
\hline Treatment satisfaction & $57.08 \pm 21.49$ & $82.63 \pm 13.21$ & $<0.01$ & $56.84 \pm 21.61$ & $82.33 \pm 13.21$ & $<0.01$ \\
\hline Quality of life & $60.27 \pm 16.70$ & $69.66 \pm 18.65$ & $<0.01$ & $60.26 \pm 17.13$ & $68.69 \pm 18.33$ & $<0.01$ \\
\hline
\end{tabular}

Anginal stability: a measure of whether a patient's symptoms are changing over time. Anginal frequency: a measure of how often a patient is having symptoms now. Physical limitation: a measure of how much a patient's condition is hampering their ability to do what they want to do. Treatment satisfaction: a measure of how well a patient understands their care and what they think of it. Quality of life: a measure of the overall impact of a patient's condition on a patient's interpersonal relationships and state of mind 
Table 5 Rates of MACE and its components by study group before and after propensity score matching

\begin{tabular}{|c|c|c|c|c|c|c|}
\hline \multirow[t]{2}{*}{ Outcome } & \multicolumn{3}{|c|}{ Before propensity score matching } & \multicolumn{3}{|c|}{ After propensity score matching } \\
\hline & $\begin{array}{l}\text { Control } \\
(N=6808)\end{array}$ & $\begin{array}{l}\text { CR } \\
(N=4001)\end{array}$ & $p$ value & $\begin{array}{l}\text { Control } \\
(N=2805)\end{array}$ & $\begin{array}{l}\text { CR } \\
(N=2805)\end{array}$ & $p$ value \\
\hline TVR & $54(0.8 \%)$ & $18(0.4 \%)$ & 0.005 & $20(0.7 \%)$ & $13(0.5 \%)$ & 0.222 \\
\hline Myocardial infarction & $37(0.5 \%)$ & $22(0.5 \%)$ & 0.398 & $20(0.7 \%)$ & $15(0.5 \%)$ & 0.397 \\
\hline Death & $21(0.3 \%)$ & $8(0.2 \%)$ & 0.292 & $7(0.2 \%)$ & $6(0.2 \%)$ & 0.781 \\
\hline MACE & 85 (1.2\%) & $34(0.8 \%)$ & - & $45(1.3 \%)$ & $24(0.8 \%)$ & - \\
\hline
\end{tabular}
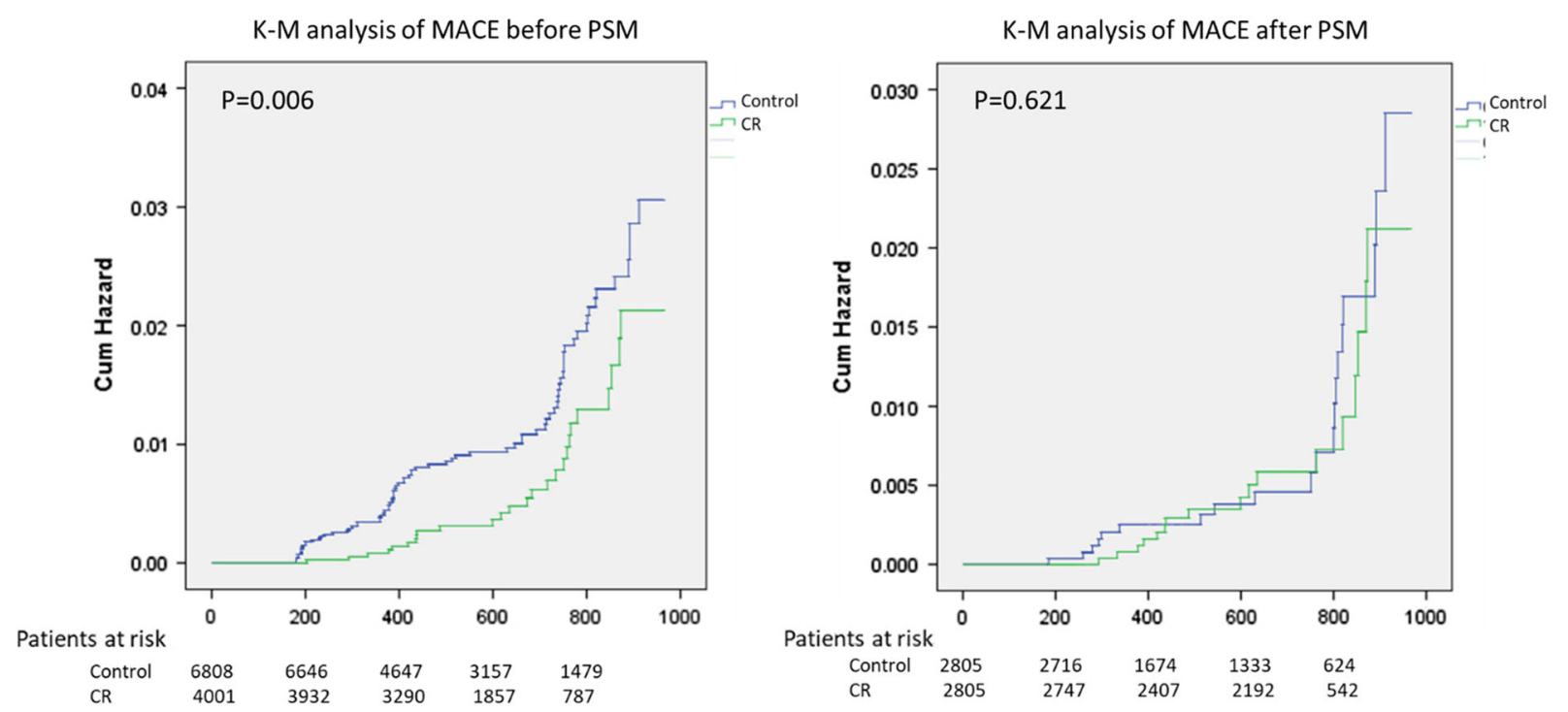

Fig. 3 Kaplan-Meier survival curves of MACE before (left) and after PSM (right)

often with unstable angina ( $63 \%$ vs. $80.7 \%$, $p<0.01)$. Moreover, this group often had less burden of risk factors for coronary artery disease, i.e., hypertension, diabetes, previous PCI, and prior stroke $(58.6$ vs. $55.3 \%, p<0.01$; $28.8 \%$ vs. $22.3 \%, p<0.01 ; 20.7 \%$ vs. $15.6 \%$, $p<0.01$; and $5.7 \%$ vs. $2.7 \%, p<0.01$, respectively) except for smoking, which was higher $(47.8 \%$ vs. $57.7 \%, p<0.01)$. After the education of $\mathrm{CR}$, the smoking rate decreased $(22.5 \%$ vs. $5.2 \%$, controls vs. CR, $p<0.01)$. In terms of medications (Table 2), the usage rates of aspirin, ticagrelor, and ACEI did not differ significantly between CR and controls, while the use of clopidogrel, $\beta$ blockers, and statins was higher in the CR group. During the treatment and follow-up, 610 patients in controls and 358 patients in the CR group crossed over between clopidogrel and ticagrelor. After propensity score matching, all baseline characteristics and medications were balanced (Tables 1,2).

\section{Outcomes After Discharge}

After PSM, both study groups were followed up after discharge (Table 3). Among controls, 956 patients did not have exercise, while in the CR group the no exercise number was 22. More patients in the CR group did a small amount of physical exercise vs. controls (2736 vs. 1849). In the CR group, 47 patients followed the exercise prescribed for rehabilitation relative to none 
among controls. Physical exercise type differed between groups $(p<0.05)$. Cumulative exercise time (hours/week) was higher in the CR group $(8.22 \pm 6.17$ vs. $3.00 \pm 1.65, P<0.05)$. Both before and after PSM, scores for the five components of the SAQ were higher for the CR groups vs. controls (all $p<0.01$; Table 4). After PSM, the physical limitation $(69.59 \pm 10.96$ vs. $57.49 \pm 7.19)$, anginal stability $(80.50 \pm 18.21$ vs. $\quad 58.82 \pm 11.95)$ anginal frequency $(78.58 \pm 11.07$ vs. $67.14 \pm 22.41)$, treatment satisfaction $(82.33 \pm 13.21$ vs. $56.84 \pm 21.61)$, and quality of life $(68.69 \pm 18.33$ vs. $60.26 \pm 17.13)$ in the CR group were all higher than those in the control group.

As Table 5 shows, at median 461 days' follow-up, incidences of adverse cardiac events in $\mathrm{CR}$ group vs. controls before and after PSM were respectively: for TVR, $0.4 \%$ vs. $0.8 \%, p=0.005$ and $0.5 \%$ vs. $0.7 \%, p=0.222$; for MI, $0.5 \%$ vs. $0.5 \%, p=0.398$ and $0.5 \%$ vs. $0.7 \%, p=0.397$; for death, $0.2 \%$ vs. $0.3 \%, p=0.292$ and $0.2 \%$ vs. $0.2 \%, p=0.781$; and for MACE, $0.8 \%$ vs. $1.2 \%$ and $0.8 \%$ vs. $1.3 \%$. However, as shown in Kaplan-Meier curves of MACE before and after PSM in Fig. 3, before PSM, cumulative hazard of MACE in controls was higher than in CR group (landmark $p=0.006$ ), while after PSM, cumulative hazard of MACE did not differ between groups (landmark $p=0.621$ ).

There were no fatal adverse events among all 4001 CR patients undergoing CPET. Only one patient suffered from ventricular tachycardia with no disturbance of consciousness and resolution 1-2 min later. Events during CPET included: posterior sternal burning pain $(n=1)$; chest tightness and shortness of breath $(n=3)$; chest tightness $(n=7)$; chest pain $(n=4)$; palpitation $(n=1)$; palpitation and ventricular bigeminy $(n=1)$; bradycardia $(n=1)$; and ventricular tachycardia $(n=1)$.

\section{DISCUSSION}

To our knowledge, the present large-scale retrospective real-world single-center study of a Chinese population post-coronary stent implantation is the first to describe long-term SAQ/clinical outcomes of a CR approach combining CPET and systematic education in hospital compared to one with only routine post-procedure education [17]. Propensity score analysis was used to compare the effectiveness of the two approaches against a background of balanced baseline characteristics. Patients receiving in-hospital CPET plus education of CR vs. controls had a more favorable type and duration of physical activity and quality of life as reflected by higher SAQ scores during followup. The latter findings may contribute to better define the most optimal CR training approach based on the particularities of patients living habits and socioeconomic conditions.

In the present study, which reflected cardiologists' choice and concern about the risk of CR/CPET for acute ACS at our center, the mean patient age was 57.42 years before propensity score matching, and the proportion of STEMI was only $10.4 \%$ in the CR group. In contrast, in a study of 1,432,399 patients who were referred to CR after PCI in the USA, the mean age was 65 years and the proportion of STEMI was $14.8 \%$ [18], and in a study of 2054 patients from 69 centers in 12 European countries, mean age was 61 years and proportion of STEMI was $22.8 \%$ [19]. The bias toward choosing patients with lower severity of disease for referral to CR is based on concern about the risk of CR/CPET, which highlights the potential requirement of interventions to break through conservative concepts and enhance CR referral rates after PCI in China.

Although high adherence and enrollment in CR could translate into improved outcomes in many studies [20], patients in real-world clinical work are less likely to complete or attend their CR programs [21-23]. A low adherence rate with $40 \%-50 \%$ of patients failing to complete their full rehabilitation programs has been reported [24], and many studies have focused on providing more effective interventions to increase the rehabilitation adherence rate [25]. The present study showed that one time of CPET and systematic education of $\mathrm{CR}$ in hospitals improved the adherence rate of home-based CR, increased Seattle angina score, and reduced smoking rate (Table 4). CR, especially physical activity, improves the tolerance of the myocardium to hypoxia and reduces the 
sympathetic activity and heart rate of patients, which will eventually improve the physical capacity and quality of life.

Incidence of anxiety and depression after ACS is as high as 50\% [26-28], which might underlie poor adherence to and enrollment in $\mathrm{CR}$, and consequently less physical activity, in patients after PCI $[29,30]$. Therefore, education of CR at our center includes psychological intervention. In the present study, after one time of CPET and education of CR, the score of Treatment Satisfaction and Quality of Life increased (Table 4). Meanwhile, physical activity categories and cumulative exercise time also improved (Table 3 ). The findings may suggest that healthy psychological status results in a higher adherence to CR. In the future, a greater variety of psychological interventions is needed in the education of $\mathrm{CR}$, such as problem-solving therapy, cognitive behavioral therapy, and interpersonal psychotherapy, as well as pharmacotherapy.

In the present study, CPET combined with education of CR before discharge significantly decreased the 'no physical exercise' rate compared with controls. However, the majority of patients engaged in only a small amount of physical exercise. Only 47 patients adhered to prescribed rehabilitation exercises. A self-report of activity from a multicenter study [31] documented a nonlinear relationship between mortality and amount of exercise, with more moderate-intensity exercise being associated with lower mortality. Other studies found that vigorous exercise may be associated with increased myocardial infarction and cardiac death [32, 33]. In the present study, no patient reported practicing vigorous exercise $>10$ METs $\mathrm{h} /$ week.

\section{Study Limitations}

The present study has the inherent limitations of its retrospective observational cohort by follow-up design. Moreover, propensity score matching was used to adjust for differences in baseline characteristics between CPET combined CR and controls, which may introduce statistical bias. The observation of MACE being different or not between $\mathrm{CR}$ and controls depending on the statistical method used suggests the possible presence of confounders not included in the analysis or differences in followup duration.

\section{CONCLUSIONS}

In this single-center experience in China, CR combining one time of cardiopulmonary function exercise with a systematic cardiac education program before discharge improved longterm physical activity and quality of life relative to only routine post-procedure education in ACS patients after PCI without increasing clinical adverse events.

\section{ACKNOWLEDGEMENTS}

Funding. This study, the Rapid Service Fee and the Open Access fee were funded by the National Natural Science Foundation of China (NSFC: 32071116) and the Lixinyangfan fund (BJUHFCSOARF201901-14).

Authorship. All named authors meet the International Committee of Medical Journal Editors (ICMJE) criteria for authorship for this article, take responsibility for the integrity of the work as a whole, and have given their approval for this version to be published.

Author contributions. Quan-Yu Zhang: performed the data analysis and wrote the manuscript; Qiang Hu: collected the data and wrote the manuscript; Yi Li: designed the experiments and checked the data; Yi Sun: follow-up visit; Jing-Fei He: follow-up visit; Miao-Han Qiu: performed the propensity score matching (PSM); Jian Zhang: scrubbed data and maintained research data; Yan-Chun Liang: performed the statistical analysis; Ya-Ling Han: conceived and designed the experiments.

Medical writing, editorial, and other assistance. All authors thank Dr. Roberto Patarca (of 
Harvard Medical School) for his revision of our manuscript.

Disclosures. Quan-Yu Zhang, Qiang $\mathrm{Hu}, \mathrm{Yi}$ Li, Yi Sun, Jing-Fei He, Miao-Han Qiu, Jian Zhang, Yan-Chun Liang, and Ya-Ling Han all declare that they have nothing to disclose.

Compliance with ethics guidelines. The Medical Ethics Committee of General Hospital of Northern Theater Command has approved our study and waived the need for patient consent. The data of patients in our study were not identifiable.

Data availability. The data underlying this article will be shared at reasonable request to the corresponding author.

Open Access. This article is licensed under a Creative Commons Attribution-NonCommercial 4.0 International License, which permits any non-commercial use, sharing, adaptation, distribution and reproduction in any medium or format, as long as you give appropriate credit to the original author(s) and the source, provide a link to the Creative Commons licence, and indicate if changes were made. The images or other third party material in this article are included in the article's Creative Commons licence, unless indicated otherwise in a credit line to the material. If material is not included in the article's Creative Commons licence and your intended use is not permitted by statutory regulation or exceeds the permitted use, you will need to obtain permission directly from the copyright holder. To view a copy of this licence, visit http://creativecommons.org/licenses/by$\mathrm{nc} / 4.0 /$.

\section{REFERENCES}

1. Rezende PC, Hueb W, Garzillo CL, et al. Ten-year outcomes of patients randomized to surgery, angioplasty, or medical treatment for stable multivessel coronary disease: effect of age in the Medicine, Angioplasty, or Surgery Study II trial. J Thorac Cardiovasc Surg. 2013;146(5):1105-12.
2. Gaglia MA Jr, Torguson R, Lipinski MJ, et al. Frequency of angina pectoris after percutaneous coronary intervention and the effect of metallic stent type. Am J Cardiol. 2016;117(4):526-31.

3. Damen NL, Versteeg H, Boersma E, et al. Indication for percutaneous coronary intervention is not associated with symptoms of anxiety and depression. Int J Cardiol. 2013;168(5):4897-8.

4. Zhao W, Bai J, Zhang F, Guo L, Gao W. Impact of completeness of revascularization by coronary intervention on exercise capacity early after acute ST-elevation myocardial infarction. J Cardiothorac Surg. 2014;9:50.

5. Lee HY, Kim JH, Kim BO, et al. Regular exercise training reduces coronary restenosis after percutaneous coronary intervention in patients with acute myocardial infarction. Int J Cardiol. 2013;167(6): 2617-22.

6. Soga Y, Yokoi H, Amemiya K, Iwabuchi M, Nobuyoshi M. Safety and efficacy of exercise training after coronary stenting in patients with stable coronary artery disease. Circ J. 2011;75(10): 2379-86.

7. Barnason S, Zimmerman L, Schulz P, Pullen C, Schuelke S. Weight management telehealth intervention for overweight and obese rural cardiac rehabilitation participants: a randomised trial. J Clin Nurs. 2019;28(9-10):1808-18.

8. Levine GN, Bates ER, Blankenship JC, et al. 2011 ACCF/AHA/SCAI Guideline for Percutaneous Coronary Intervention. A report of the American College of Cardiology Foundation/American Heart Association Task Force on Practice Guidelines and the Society for Cardiovascular Angiography and Interventions. J Am Coll Cardiol. 2011;58(24):e44122.

9. Zhang Z, Pack Q, Squires RW, Lopez-Jimenez F, Yu L, Thomas RJ. Availability and characteristics of cardiac rehabilitation programmes in China. Heart Asia. 2016;8(2):9-12.

10. Section of Interventional Cardiology of Chinese Society of Cardiology of Chinese Medical A, Specialty Committee on P, Treatment of Thrombosis of Chinese College of Cardiovascular P, Editorial Board of Chinese Journal of C. [Chinese guideline for percutaneous coronary intervention(2016)]. Zhonghua Xin Xue Guan Bing Za Zhi. 2016;44(5): 382-400.

11. Fletcher GF, Ades PA, Kligfield P, et al. Exercise standards for testing and training. Circulation. 2013;128(8):873-934. 
12. Commitee of Cardiac R, Prevention of Chinese Association of Rehabilitation M. [Guidelines for cardiovascular rehabilitation and secondary prevention in China 2018 simplified edition]. Zhonghua Nei Ke Za Zhi. 2018;57(11):802-10.

13. Chan PS, Jones PG, Arnold SA, Spertus JA. Development and validation of a short version of the Seattle angina questionnaire. Circ Cardiovasc Qual Outcomes. 2014;7(5):640-7.

14. Hicks KA, Tcheng JE, Bozkurt B, et al. 2014 ACC/ AHA Key Data Elements and Definitions for Cardiovascular Endpoint Events in Clinical Trials: a Report of the American College of Cardiology/ American Heart Association Task Force on Clinical Data Standards (Writing Committee to Develop Cardiovascular Endpoints Data Standards). J Am Coll Cardiol. 2015;66(4):403-69.

15. Thygesen K, Alpert JS, Jaffe AS, et al. Fourth universal definition of myocardial infarction (2018). Circulation. 2018;138(20):e618-51.

16. Hansen D, Dendale P, Coninx K, et al. The European Association of Preventive Cardiology Exercise Prescription in Everyday Practice and Rehabilitative Training (EXPERT) tool: A digital training and decision support system for optimized exercise prescription in cardiovascular disease. Concept, definitions and construction methodology. Eur J Prev Cardiol. 2017;24(10):1017-31.

17. Kirolos I, Yakoub D, Pendola F, et al. Cardiac physiology in post myocardial infarction patients: the effect of cardiac rehabilitation programs-a systematic review and update meta-analysis. Ann Transl Med. 2019;7(17):416.

18. Aragam KG, Dai D, Neely ML, et al. Gaps in referral to cardiac rehabilitation of patients undergoing percutaneous coronary intervention in the United States. J Am Coll Cardiol. 2015;65(19):2079-88.

19. Benzer W, Rauch B, Schmid JP, et al. Exercise-based cardiac rehabilitation in twelve European countries results of the European cardiac rehabilitation registry. Int J Cardiol. 2017;228:58-67.

20. Dalal HM, Doherty P, Taylor RS. Cardiac rehabilitation. BMJ. 2015;351:5000.

21. Cortes O, Arthur HM. Determinants of referral to cardiac rehabilitation programs in patients with coronary artery disease: a systematic review. Am Heart J. 2006;151(2):249-56.

22. Chamosa S, Alarcon JA, Dorronsoro M, et al. Predictors of Enrollment in Cardiac Rehabilitation Programs in Spain. J Cardiopulm Rehabil Prev. 2015;35(4):255-62.
23. Bethell HJ, Turner SC, Evans JA, Rose L. Cardiac rehabilitation in the United Kingdom. How complete is the provision? J Cardiopulm Rehabil. 2001;21(2):111-5.

24. Sanderson BK, Phillips MM, Gerald L, DiLillo V, Bittner V. Factors associated with the failure of patients to complete cardiac rehabilitation for medical and nonmedical reasons. J Cardiopulm Rehabil. 2003;23(4):281-9.

25. Matata BM, Williamson SA. A review of interventions to improve enrolment and adherence to cardiac rehabilitation among patients aged 65 years or above. Curr Cardiol Rev. 2017;13(4):252-62.

26. Akhtar MS, Malik SB, Ahmed MM. Symptoms of depression and anxiety in post-myocardial infarction patients. J Coll Physicians Surg Pak. 2004;14(10):615-8.

27. Sever S, Golder S, Doherty P. Factors associated with acute depressive symptoms in patients with comorbid depression attending cardiac rehabilitation. BMC Cardiovasc Disord. 2018;18(1):230.

28. Janszky I, Ahnve S, Lundberg I, Hemmingsson T. Early-onset depression, anxiety, and risk of subsequent coronary heart disease: 37-year follow-up of 49,321 young Swedish men. J Am Coll Cardiol. 2010;56(1):31-7.

29. Lavie CJ, Milani RV. Cardiac rehabilitation, exercise training, and psychosocial risk factors. J Am Coll Cardiol. 2006;47(1):212.

30. Wallert J, Gustafson E, Held C, et al. Predicting adherence to internet-delivered psychotherapy for symptoms of depression and anxiety after myocardial infarction: machine learning insights from the U-CARE Heart Randomized Controlled Trial. J Med Internet Res. 2018;20(10):10754.

31. Stewart RAH, Held C, Hadziosmanovic N, et al. Physical activity and mortality in patients with stable coronary heart disease. J Am Coll Cardiol. 2017;70(14):1689-700.

32. Mittleman MA, Maclure M, Tofler GH, Sherwood JB, Goldberg RJ, Muller JE. Triggering of acute myocardial infarction by heavy physical exertion. Protection against triggering by regular exertion. Determinants of Myocardial Infarction Onset Study Investigators. N Engl J Med. 1993;329(23):1677-83.

33. Albert CM, Mittleman MA, Chae CU, Lee IM, Hennekens $\mathrm{CH}$, Manson JE. Triggering of sudden death from cardiac causes by vigorous exertion. N Engl J Med. 2000;343(19):1355-61. 